\section{Controlled, Copper-Catalyzed Functionalization of Polyolefins}

M. Mar Díaz-Requejo, ${ }^{\dagger}$ Peter Wehrmann, ${ }^{\ddagger}$ Mark D. Leatherman, ${ }^{\S}$ Swiatoslaw Trofimenko, ${ }^{\perp}$ Stefan Mecking, ${ }^{\ddagger}$ Maurice Brookhart,${ }^{\S}$ and Pedro J. Pérez ${ }^{* \dagger}$

Laboratorio de Catálisis Homogénea, Departamento de Química y Ciencia de los Materiales, Unidad Asociada al CSIC, Campus de El Carmen s/n, Universidad de Huelva, 21007-Huelva, Spain; Department of Chemistry and Biochemistry, University of Delaware, Newark, Delaware 19716; Department of Chemistry, University of North Carolina, Chapel Hill, CB3290, Chapel Hill, North Carolina 27599; and Universität Konstanz, Fachbereich Chemie, 78457 Konstanz, Germany

Introduction. Polyolefins are produced on a vast scale approaching 100 million tons annually. ${ }^{\text {1a }}$ The majority of this material is prepared through metalcatalyzed processes. Introduction of polar groups along the polymer backbone can yield materials with advantageous properties regarding adhesion on polar surfaces, barrier properties, and solvent resistance. Commercial synthesis of such materials is carried out primarily through radical-initiated copolymerization of ethylene with polar vinyl monomers (e.g., a few percent of vinyl acetate) at very high pressures and high temperatures since the polar monomers are incompatible with currently used metal catalysts. Although significant advances have been achieved in transition-metal-catalyzed copolymerization of ethylene and 1-olefins with polar monomers, ${ }^{1 b-f}$ polymerization rates are much lower by comparison to commercial polyolefin production, and the scope of monomers utilizable is limited. The currently practiced radical processes provide little control of polymer microstructure and molecular weight. An alternative approach to preparing such materials with potentially better structural control is to incorporate the polar functionality a posteriori, that is, after the polymer has been formed. In the case of polymers containing unsaturated $\mathrm{C}-\mathrm{C}$ bonds, postpolymerization modifications are available by means of several transformations including epoxidation, hydroboration, chlorosilation, and carbene addition. ${ }^{2}$ However, in the case of polyolefins, this methodology becomes a challenge due to the lack of reactive functional groups. Previous work has been mainly focused on polypropylene, ${ }^{3,4}$ for which several procedures have been developed. Most are radical-based initiated by peroxide decomposition at high temperatures. A major drawback of these methods is the significant chain scission under the severe reaction conditions. Carbene insertion into the carbon-hydrogen bonds of the polymer chains has also been used to functionalize polymers (PP and $\mathrm{PE})$ : diazoacetate decomposition at high temperature $\left(>200^{\circ} \mathrm{C}\right)$ was reported by Aglietto and co-workers in the mid-1980s. ${ }^{5}$ Oxidation of polyolefins has also been achieved by catalytic

\footnotetext{
Universidad de Huelva-CSIC.

$\doteqdot$ Universität Konstanz.

$\S$ University of North Carolina.

$\perp$ University of Delaware.

* Corresponding author: e-mail perez@dqcm.uhu.es.
}

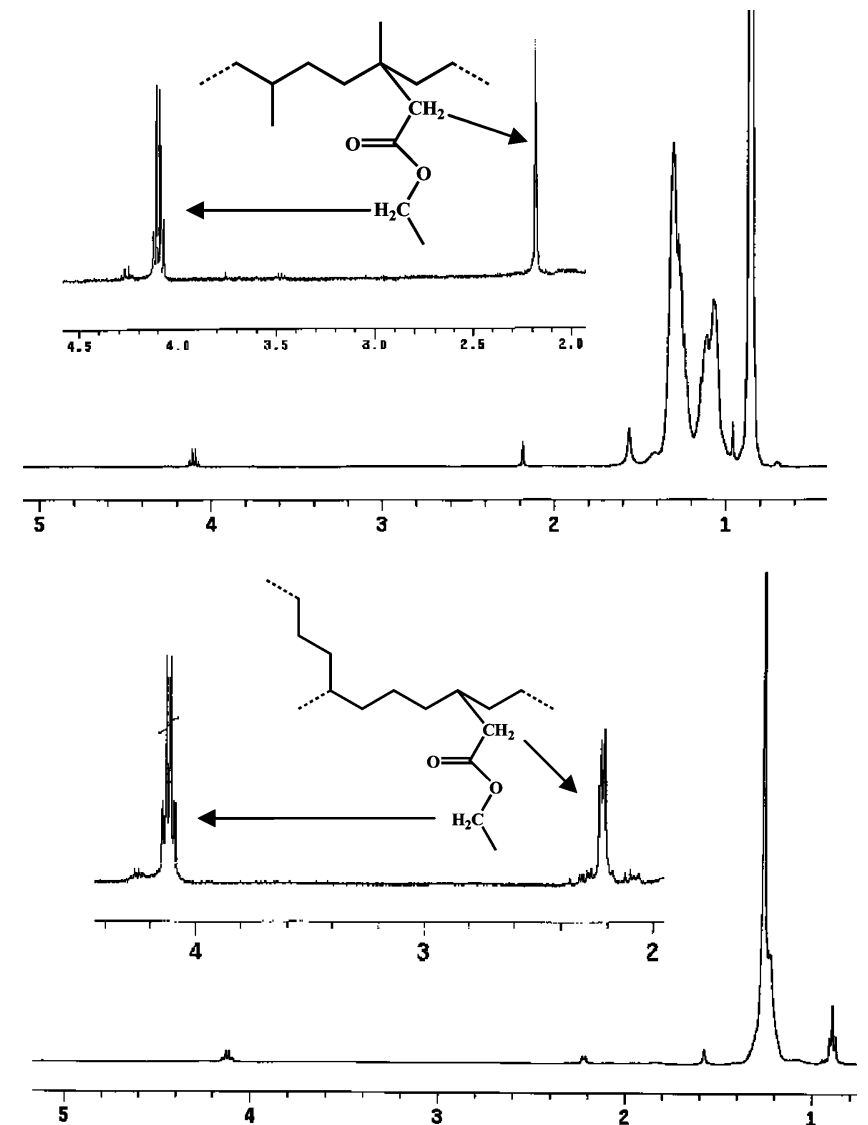

Figure 1. ${ }^{1} \mathrm{H}$ NMR spectrum of (a) top, modified polybutene $\left(\mathrm{CDCl}_{3}, 400 \mathrm{MHz}\right)$; (b) bottom, modified poly(ethylene-co-1octene) $\left(\mathrm{CDCl}_{3}, 400 \mathrm{MHz}\right)$.

methods. Hillmyer and Hartwig et al. have described metal-based catalysts for the oxyfunctionalization of polyethylene-alt-polypropylene, ${ }^{6}$ polyethylene,${ }^{7}$ and commercial polypropylene ${ }^{8}$ that convert terminal $\mathrm{C}-\mathrm{H}$ bonds into hydroxyl groups.

Results and Discussion. We have recently developed a copper-based catalytic system for the functionalization of alkanes through insertion of $\mathrm{CHCO}_{2} \mathrm{Et}$ into $\mathrm{C}-\mathrm{H}$ bonds using commercial ethyl diazoacetate (EDA) as the carbene source. ${ }^{9}$ The catalysts employed for this transformation were the $\mathrm{Tp}^{\mathrm{x}} \mathrm{Cu}(\mathrm{NCMe})$ complexes $\left(\mathrm{Tp}^{\mathrm{x}}\right.$ $=$ hydrotris(pyrazolyl)borate or homoscorpionate)..$^{10}$ However, the application of this procedure using any family of catalysts to polyolefin $\mathrm{C}-\mathrm{H}$ bonds is so far yet unreported. We present here the catalytic reaction of EDA with polyolefins in the presence of the complex $\mathrm{Tp}^{\mathrm{Br} 3} \mathrm{Cu}(\mathrm{NCMe})(\mathbf{1})\left(\mathrm{Tp}^{\mathrm{Br} 3}=\right.$ hydrotris $(3,4,5$-tribromopyrazolyl)borate) as the catalyst, which has allowed the controlled incorporation of ester groups in the chains of saturated hydrocarbon polymers.

The polymerization of trans-2-butene with ( $\alpha$-diimine)Ni(II) catalysts ${ }^{11}$ provides a high molecular weight polyolefin with a well-defined structure corresponding to a linear polyethylene with a methyl branch on every third carbon atom precisely (Scheme 1). We have carried out the room temperature reaction of ethyl diazoacetate and the poly $(2 \text {-butene })^{12}$ in the presence of catalytic amounts of $\mathrm{Tp}^{\mathrm{Br}}{ }^{3} \mathrm{Cu}(\mathrm{NCMe})$ (Scheme 1). After work-up, NMR studies ${ }^{13}$ of the isolated product revealed the exclusive incorporation of : $\mathrm{CHCO}_{2} \mathrm{Et}$ units into tertiary 
Scheme 1. Functionalization of Poly(1-butene) by EDA Insertion Catalyzed by $\mathrm{Tp}^{\mathrm{Br} 3} \mathrm{Cu}(\mathrm{NCMe})$<smiles></smiles><smiles>CCC(C)(C)CCC(C)C(C)(C)CCC(C)(C)CCC(C)(C)C(C)C</smiles>

$\mathrm{Tp}^{\mathrm{Br} 3}$

Table 1. Polymer Functionalization ${ }^{a}$ by Ethyl Diazoacetate Insertion Using $\operatorname{Tp}^{\mathrm{Br} 3}{ }^{\mathrm{Cu}}(\mathrm{NCMe})(1)$ as the Catalyst

\begin{tabular}{|c|c|c|c|c|c|c|}
\hline entry & polymer $\left(M_{\mathrm{w}}, M_{\mathrm{n}}, \mathrm{PDI}\right)^{e}$ & catalyst loading ${ }^{b}$ & polymer:EDA ${ }^{c}$ & $\begin{array}{c}\text { addn } \\
\text { time (h) }\end{array}$ & $\begin{array}{l}\mathrm{CO}_{2} \mathrm{Et} / \\
1000 \mathrm{C}^{d}\end{array}$ & $\operatorname{product}\left(M_{\mathrm{w}}, M_{\mathrm{n}}, \mathrm{PDI}\right)^{e}$ \\
\hline 1 & polybutene $(288,151,1.9)$ & 2.5 & $1: 3$ & 4 & 10 & $281,164,1.71$ \\
\hline 2 & polybutene $(288,151,1.9)$ & 2.5 & $1: 3$ & 8 & 11 & $303,163,1.87$ \\
\hline 3 & polybutene $(288,151,1.9)$ & 3.0 & $1: 6$ & 6 & 9.6 & $337,191,1.77$ \\
\hline 4 & poly(ethylene-1-octene) $(63,30,2.08)$ & 1.5 & 1:1.5 & 3 & 4.7 & $67,35,1.93$ \\
\hline 5 & poly(ethylene-1-octene) $(63,30,2.08)$ & 1.5 & $1: 1.5$ & 6 & 5.1 & $66,32,2.05$ \\
\hline 6 & poly(ethylene-1-octene) $(63,30,2.08)$ & 3.0 & 1:1.5 & 6 & 4.0 & $64,31,2.05$ \\
\hline 7 & poly(ethylene-1-octene) $(63,30,2.08)$ & 1.5 & $1: 3$ & 6 & 10.7 & $67,33,2.04$ \\
\hline 8 & poly(ethylene-1-octene) $(63,30,2.08)$ & 1.5 & $1: 6$ & 6 & 17.5 & $66,31,2.14$ \\
\hline 9 & poly(ethylene-1-octene) $(63,30,2.08)$ & 3.0 & $1: 6$ & 6 & 20.0 & $67,33,2.03$ \\
\hline 10 & poly(ethylene-1-octene) $(63,30,2.08)$ & 1.5 & $1: 12$ & 6 & 31.7 & $100,57,1.76^{15}$ \\
\hline 11 & poly(ethylene-1-octene) $(63,30,2.08)$ & 5.0 & $1: 1.5$ & 6 & 3.0 & $69,30,2.16$ \\
\hline
\end{tabular}

${ }^{a}$ See ref 12. ${ }^{b}$ Molar percent relative to moles of monomer repeat units. ${ }^{c}$ Ratio of mol repeat units of polymer:mol of EDA. ${ }^{d}$ Determined by ${ }^{1} \mathrm{H}$ NMR. ${ }^{e}$ Determined by GPC vs narrow linear polyethylene standards $\left(160^{\circ} \mathrm{C}\right.$, trichlorobenzene). $M_{\mathrm{w}}$ and $M_{\mathrm{n}}$ values $\times 10^{-3} \mathrm{~g}$ mol ${ }^{-1}$.

carbon-hydrogen bonds. Figure 1 shows the ${ }^{1} \mathrm{H}$ NMR spectrum of the functionalized polymer. The $-\mathrm{CH}_{2}-$ $\mathrm{CO}_{2}$ Et fragments are unambiguously assigned to the resonances centered at $4.05\left(\mathrm{q}, 2 \mathrm{H},-\mathrm{CO}_{2} \mathrm{CH}_{2}-\mathrm{CH}_{3}\right)$ and $2.18\left(\mathrm{~s}, 2 \mathrm{H},-\mathrm{CH}_{2}-\mathrm{CO}_{2} \mathrm{CH}_{2}-\mathrm{CH}_{3}\right)$, the methyl group of the carboxylate fragment being obscured by the polymeric chain resonances. The degree of incorporation (determined by NMR) was ca. 10-11 $\mathrm{CO}_{2} \mathrm{Et} / 1000 \mathrm{C}$, corresponding to ca. $4 \%$ of the tertiary sites, depending on the reaction conditions. A significant feature of this methodology was revealed by GPC of the functionalized materials (Table 1 , entries $1-3) .{ }^{14}$ The molecular weights determined for the products do not differ significantly from those of the products, a fact that should be interpreted as a consequence of the lack of chain scission processes. Note that molecular weights are apparent molecular weights relative to linear polyethylene standards; i.e., changes in the hydrodynamic behavior of the polymer upon functionalization are to be expected to result in some changes of the observed relative molecular weights.

Having established the potential of complex $\mathbf{1}$ to catalyze the insertion of $: \mathrm{CHCO}_{2} \mathrm{Et}$ fragments into carbon-hydrogen bonds of polybutene, we investigated this methodology in more detail employing a random copolymer of ethylene and 1-octene (40 wt \% in 1-octene, Dow Engage type) as a substrate. The reaction of this material with 1/EDA was carried out in a manner similar to that described for poly(2-butene). ${ }^{12}$ In this case, in contrast to poly(2-butene), incorporation of EDA took place into secondary $\mathrm{C}-\mathrm{H}$ bonds preferentially. As shown in Figure 1 , the ${ }^{1} \mathrm{H}$ NMR spectrum ${ }^{13}$ of the modified polymer displays again the resonances attributable to $-\mathrm{CH}_{2}-\mathrm{CO}_{2}$ Et groups with similar patterns to those observed in the functionalization of smaller alkanes. ${ }^{8 c}$ Although some tertiary activation could occur, the observation of a doublet for $-\mathrm{CH}_{2}-\mathrm{CO}_{2} \mathrm{CH}_{2}-\mathrm{CH}_{3}$ is consistent with the insertion of EDA into a secondary $\mathrm{C}-\mathrm{H}$ bond, therefore leading to $-\mathrm{CH}\left(-\mathrm{CH}_{2}-\mathrm{CO}_{2} \mathrm{Et}\right)-$ fragments along the chain. The existence of a large

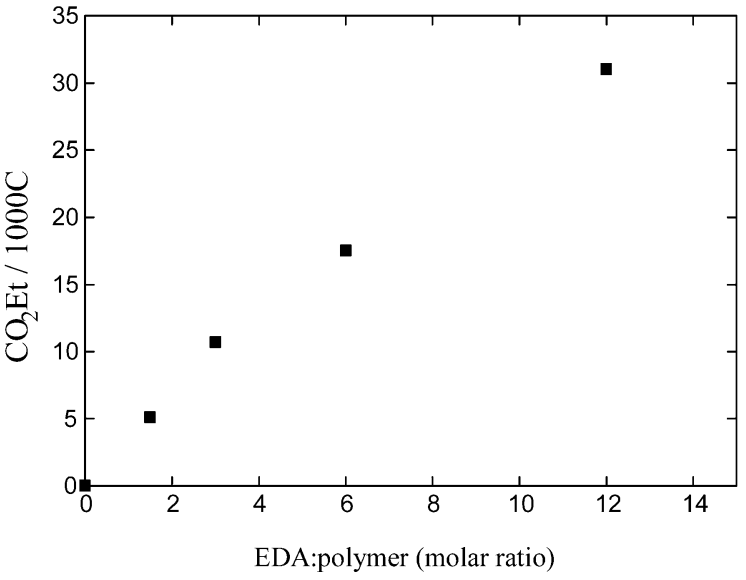

Figure 2. Correlation between the degree of functionalization $\left(\mathrm{CO}_{2} \mathrm{Et} / 1000 \mathrm{C}\right)$ of poly(ethylene-co-1-octene) and the EDA: polymer ratio (molar ratio repeat units/EDA) employed.

number of such methylene sites in comparison with the tertiary $\mathrm{C}-\mathrm{H}$ bonds (only 45 branches/1000C vs 250 / 1000 for poly(2-butene)) along with a more open steric environment of the majority of the methylene units rationalizes this behavior. This could also account for the observed increase in the degree of ester group incorporation (in terms of the number of carboxylates per 1000C), as inferred from the data in entries 3 and 9 in Table 1 . These results are in good agreement with the observed regioselectivity in the case of 2-methylbutane and 2-methylpentane. ${ }^{9}$ High-temperature GPC of the functionalized polyolefins and the products clearly reveals that no chain scission occurs. ${ }^{14,15}$

Since control of the degree of ester incorporation is desirable due to its relationship to polymer properties, we have performed a series of experiments where we have modified the following variables: (i) EDA addition time, (ii) catalyst loading, and (iii) polymer:EDA ratio (Table 1, entries 4-11). Although each of them exerts a certain degree of influence in the number of : $\mathrm{CHCO}_{2}-$ 

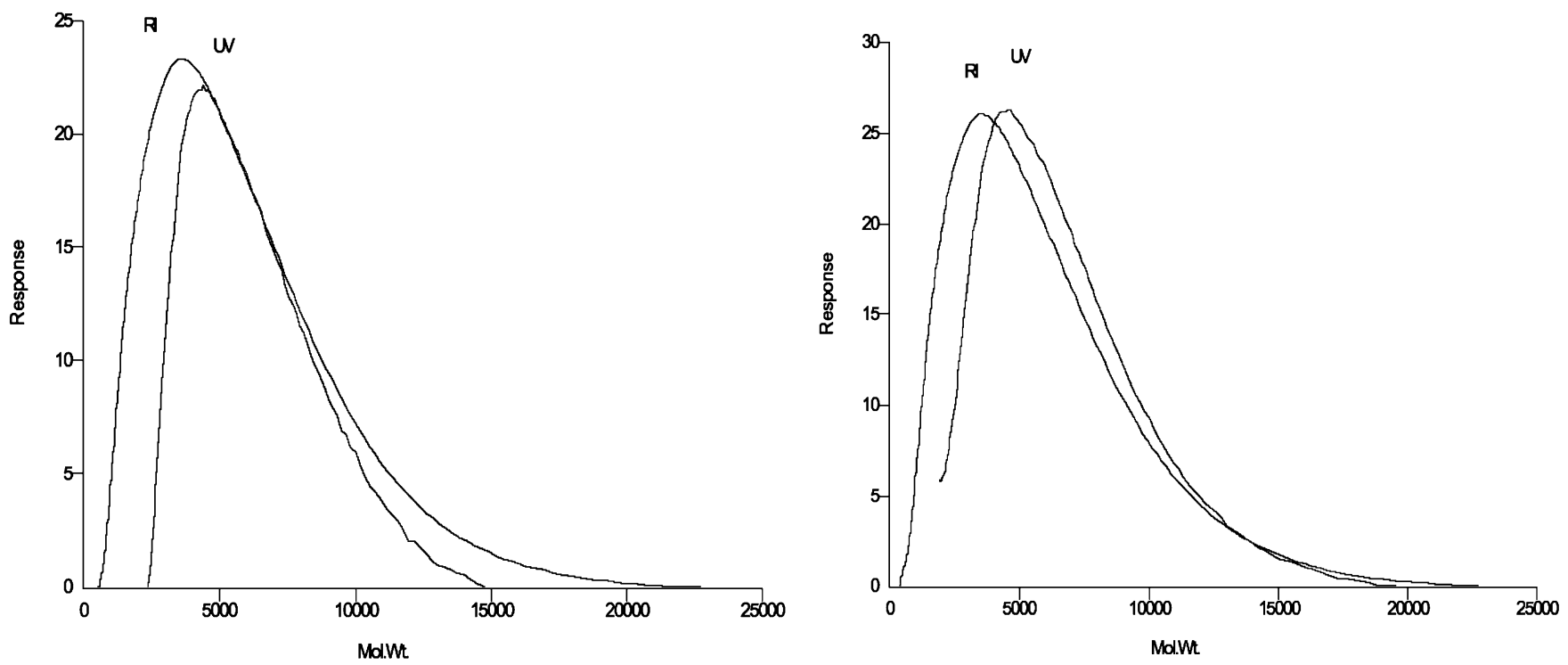

Figure 3. GPC traces (THF, $40{ }^{\circ} \mathrm{C}, \mathrm{RI}$ and UV detection vs polystyrene standards) for functionalized atactic polypropylene oligomer (reaction conditions, cf. Table 1 and general experimental procedure; $5 \%$ catalyst; addition time EDA 3 h). Left: polymer repeat units:EDA 1:1.5, incorporation: $1.9 \mathrm{CO}_{2} \mathrm{Et} / 1000 \mathrm{C}$. Right: polymer repeat units:EDA 1:2, incorporation: $2.6 \mathrm{CO}{ }_{2} \mathrm{Et} / 1000 \mathrm{C}$.

Et groups incorporated, the EDA:polymer ratio seems to be the predominant factor. Figure 2 shows the variation of the degree of incorporation, at a fixed addition rate and catalyst loading, with respect to such ratio, for the poly(ethylene-co-1-octene) case: it is quite evident that this system enables control of the number of ester groups incorporated into the polymer chain.

Functionalization of an atactic, saturated polypropylene oligomer ( $M_{\mathrm{n}} 2500$ vs polystyrene standards) was also studied. This starting material was chosen as this polymer, and the functionalized products are sufficiently soluble in nonaromatic solvents at moderate temperatures (THF, $40^{\circ} \mathrm{C}$ ), enabling GPC analysis with simultaneous RI and UV detection. Whereas IR detection is nonspecific, the UV detection is selective for the ester groups introduced. ${ }^{14}$ An overlay of RI- and UV-detected GPC traces demonstrates (see Figure 3) that the functional groups are introduced evenly over the entire molecular weight range. On the other hand, NMR studies showed that incorporation of the $: \mathrm{CHCO}_{2} \mathrm{Et}$ groups took place mainly into secondary sites, but with some tertiary $\mathrm{C}-\mathrm{H}$ bond functionalization as well.

In conclusion, the results described herein represent a new method to introduce polar ester groups into polyolefin chains, distinct to all those reported to date in operating under mild conditions without any observable chain scission in a one-step procedure. Control of the extent of ester group incorporation can be achieved through varying the ratio of $1 / \mathrm{EDA}$ to polyolefin. The versatility of the method has been demonstrated also for a commercial standard polyolefin.

Acknowledgment. We thank the MCYT (Proyecto BQU2002-01114) for financial support and the Universidad de Huelva for the Servicio de Resonancia Magnética Nuclear. M.M.D.R. thanks MCYT (Spain) for a postdoctoral fellowship. M.B. and M.D.L. thank NSF (CHE-0107810) for support. Support by a DAAD travel grant is acknowledged.

\section{References and Notes}

(1) (a) Galli, P.; Vecellio. G. J. Polym. Sci., Part A 2004, 42, 396. (b) Johnson, L. K.; Mecking, S.; Brookhart, M. J. Am. Chem. Soc. 1996, 118, 267. (c) Mecking, S.; Johnson, L. K. Wang, L.; Brookhart, M. J. Am. Chem. Soc. 1998, 120, 888 Reviews: (d) Ittel, S. D.; Johnson, L. K.; Brookhart, M. Chem. Rev. 2000, 100, 1169. (e) Mecking, S. Angew. Chem. 2001, 113, 550-557; Angew. Chem., Int. Ed. 2001, 40, 534540. (f) Boffa, L. S.; Novak, B. M. Chem. Rev. 2000, 100 1479-94. (g) Gibson, V. C.; Spitzmesser, S. K. Chem. Rev. 2003, 103, 283-316.

(2) McGrath, M. P.; Sall, E. D.; Tremont, S. J. Chem. Rev. 1995, $95,381$.

(3) Guyot, A. Polym. Adv. Technol. 1996, 7, 61.

(4) Verney, V.; Koerper, E.; Michel, A. Makromol. Chem., Macromol. Symp. 1989, 25, 187.

(5) (a) Skell, P. S.; Aglietto, M.; Ruggeri, G.; Speranza, S.; Ciardelli, F. Italian Patent 48950A/85, 1985. (b) Aglietto, M.; Bertani, R.; Ruggeri, G.; Fiordiponti, P.; Segre, A. L. Macromolecules 1989, 22, 1492. (c) Aglietto, M.; Alterio, R.; Bertani, R.; Galleschi, F.; Ruggeri, G. Polymer 1989, 30, 1133.

(6) (a) Boaen, N. K.; Hillmyer, M. A. Polymer Prepr. 2003, 44, 802. (b) Boaen, N. K.; Hillmyer, M. A. Macromolecules 2003, 36,7027

(7) Kondo, Y.; García-Cuadrado, D.; Hartwig, J. F.; Boaen, N. K.; Wagner, N. L.; Hillmyer, M. A. J. Am. Chem. Soc. 2002, 124,1164 .

(8) Bae, C.; Hartwig, J. F.; Boaen-Harris, N. K.; Long, R. O.; Anderson, K. S.; Hillmyer, M. A. J. Am. Chem. Soc. 2005, $127,767$.

(9) (a) Díaz-Requejo, M. M.; Belderrain, T. R.; Nicasio, M. C.; Trofimenko, S.; Pérez, P. J. J. Am. Chem. Soc. 2002, 124, 896. (b) Caballero, A.; Díaz-Requejo, M. M.; Belderrain, T. R.; Nicasio, M. C.; Trofimenko, S.; Pérez, P. J. J. Am. Chem. Soc. 2003, 125, 1446. (c) Caballero, A.; Díaz-Requejo, M. M.; Belderrain, T. R.; Nicasio, M. C.; Trofimenko, S.; Pérez, P. J. Organometallics 2003, 22, 4145 .

(10) Trofimenko, S. Scorpionates, The Coordination Chemistry of Polypyrazolylborate ligands; Imperial College Press: London, 1999.

(11) Leatherman, M. D.; Brookhart, M. Macromolecules 2001, $34,2748$.

(12) General experimental procedure: (a) polybutene ( $0.1 \mathrm{~g}$ ) was stirred in a mixture of dichloromethane $(5 \mathrm{~mL})$ and hexane $(1 \mathrm{~mL})$ until dissolution, and then catalyst was added. A solution of the desired amount of ethyl diazoacetate in 10 $\mathrm{mL}$ of $\mathrm{CH}_{2} \mathrm{Cl}_{2}$ was then added, at room temperature, with the aid of a syringe pump. After completion, no EDA was observed by GC. The volume was reduced to $1 \mathrm{~mL}$, and then methanol was added $(70 \mathrm{~mL})$. The resulting solid was filtered off and washed with methanol $(2 \times 40 \mathrm{~mL})$. Further 
filtration and drying under vacuum gave the functionalized polymers in $85-90 \%$ isolated yields. (b) Poly(ethylene-1octene): $0.2 \mathrm{~g}$ was dissolved in a mixture of toluene $(5 \mathrm{~mL})$ and dichloromethane $(5 \mathrm{~mL})$. Following the above procedure, white solids were isolated in 85-90\%. (c) Polypropylene was functionalized following the above procedure for polybutene.

(13) Selected NMR data for functionalized polybutene. ${ }^{1} \mathrm{H}$ NMR $\left(\mathrm{CDCl}_{3}, 400 \mathrm{MHz}\right): \delta 2.18\left(\mathrm{br} \mathrm{s},-\mathrm{CH}_{2}-\mathrm{CO}_{2} \mathrm{Et}\right.$ ), 4.05 (q $\left.\mathrm{CO}_{2} \mathrm{CH}_{2} \mathrm{CH}_{3}\right) .{ }^{13} \mathrm{C}\left\{{ }^{1} \mathrm{H}\right\}$ NMR: $\delta 172.8\left(\mathrm{CH}_{2} \mathrm{CO}_{2} \mathrm{CH}_{2} \mathrm{CH}_{3}\right)$, $60.2\left(\mathrm{CH}_{2} \mathrm{CO}_{2} \mathrm{CH}_{2} \mathrm{CH}_{3}\right), 44.3\left(\mathrm{CH}_{2} \mathrm{CO}_{2} \mathrm{CH}_{2} \mathrm{CH}_{3}\right)$ and 14.6 $\left(\mathrm{CH}_{2} \mathrm{CO}_{2} \mathrm{CH}_{2} \mathrm{CH}_{3}\right)$. Selected NMR data for functionalized poly(ethylene-1-octene). ${ }^{1} \mathrm{H}$ NMR $\left(\mathrm{CDCl}_{3}, 400 \mathrm{MHz}\right): \delta 2.22$ (br d, $-\mathrm{R}\left(\mathrm{R}^{\prime}\right) \mathrm{CH}-\mathrm{CH}_{2}-\mathrm{CO}_{2} \mathrm{Et}$ ), $4.08\left(\mathrm{q}, \mathrm{CO}_{2} \mathrm{CH}_{2} \mathrm{CH}_{3}\right),{ }^{13} \mathrm{C}-$ $\left\{{ }^{1} \mathrm{H}\right\}$ NMR: $\delta 173.7\left(-\mathrm{R}\left(\mathrm{R}^{\prime}\right) \mathrm{CH}-\mathrm{CH}_{2} \mathrm{CO}_{2} \mathrm{CH}_{2} \mathrm{CH}_{3}\right), 60.3$ $\left(\mathrm{CH}_{2} \mathrm{CO}_{2} \mathrm{CH}_{2} \mathrm{CH}_{3}\right), 39.7\left(\mathrm{R}\left(\mathrm{R}^{\prime}\right) \mathrm{CH}-\mathrm{CH}_{2} \mathrm{CO}_{2} \mathrm{CH}_{2} \mathrm{CH}_{3}\right)$. Selected NMR data for functionalized polypropylene. ${ }^{1} \mathrm{H}$ NMR $\left(\mathrm{CDCl}_{3}, 400 \mathrm{MHz}\right): \delta 2.20\left(\right.$ br m, $-\mathrm{R}\left(\mathrm{R}^{\prime}\right) \mathrm{CH}-\mathrm{CH}_{2}-\mathrm{CO}_{2} \mathrm{Et}$, secondary activation), $2.22\left(\mathrm{~s},-\mathrm{R}\left(\mathrm{R}^{\prime}\right)\left(\mathrm{R}^{\prime \prime}\right) \mathrm{C}-\mathrm{CH}_{2}-\mathrm{CO}_{2} \mathrm{Et}\right.$, tertiary activation) 4.09 (q, $\left.\mathrm{CO}_{2} \mathrm{CH}_{2} \mathrm{CH}_{3}\right)$.

(14) Molecular weight determination of polymers was carried out on a PL GPC-220 instrument equipped with a mixed B column set in trichlorobenzene at $160^{\circ} \mathrm{C}$. Data are referenced vs narrow polyethylene standards. The atactic lowmolecular-weight polypropylene samples were analyzed on a PL GPC-50 instrument at room temperature in THF, employing refractive index and UV-vis detection. Data are referenced to polystyrene standards.

(15) The increased apparent molecular weight of the functionalized product in entry 9 stands out. Changes in hydrodynamic behavior by functionalization (cf. discussion of poly(2butene) functionalization) probably can account for the observed effect only partially, comparing these data with that of all other polymers. 